\title{
Vulnerability to Poverty: Tajikistan during and after the Global Financial Crisis.
}

Ira N. Gang, Rutgers University (gang@rutgers.edu)

Kseniia Gatskova, IOS-Regensburg (gatskova@ios-regensburg.de)

John Landon-Lane, Rutgers University (lane@economics.rutgers.edu)

*Myeong-Su Yun, Inha University, (msyun@inha.ac.kr)

* Corresponding author

June 9, 2010

\begin{abstract}
We examine vulnerability to poverty in Tajikistan during the global financial crisis, focusing on the roles played by international migration and remittances, using a formal, practical, and easily decomposable vulnerability measure. Our strategy is to estimate a Markov transition probability matrix with the aim of identifying the vulnerability of households to poverty. Importantly, by introducing the index of vulnerability as the weighted probability of a household falling into poverty over a given time horizon, we can use the estimated dynamics to assess the short, medium and long-run vulnerability. We find that during the "recession transition" almost all households were vulnerable to poverty while almost none were during the "recovery period". Overall, urban households, more educated households and households receiving remittances from international labor migrants were less vulnerable to poverty. While households with a current or very recent migrant did not have a significantly lower measured vulnerability to poverty, those households receiving remittances from migrants had a lower vulnerability to poverty. Our findings stress that the international labor migration from Tajikistan may not be considered as a reliable means of welfare security for the households because external economic shocks and internal political decisions may negatively affect Russian economy and lead to a reduction of remittances flow to Tajikistan. (207 words)
\end{abstract}

Keywords: mobility measurement, vulnerability, poverty, inequality, measurement, Tajikistan JEL classification: J60, D63, I32

Addresses: Ira N. Gang, Economics, Rutgers University, 75 Hamilton St., New Brunswick, NJ 08901-1248 USA, email: gang@rutgers.edu, phone: +1 848 932-8648, fax: +1 732 932-7416; Kseniia Gatskova, IOS-Regensburg, D-93047 Regensburg, GERMANY, email: gatskova@ios-regensburg.de, phone: +49 941 94354-10, fax: +49 941 94354-27; John LandonLane, Economics, Rutgers University, 75 Hamilton St., New Brunswick, NJ 08901-1248 USA, email: lane@economics.rutgers.edu, phone: +1 848 932-8888, fax: +1 732 932-7416; MyeongSu Yun, Economics, Inha University, 100 Inharo Nam-gu Incheon 22212, Korea (South), email: msyun@inha.ac.kr, phone: +82 32 860-7779. fax: +82 32 860-7772.

Acknowledgements: We thank Ilhom Abdulloev and Melanie Khamis for long conversations on this material, and IOS-Regensburg for the data. An earlier version was presented at the UNUWIDER Conference: Inequality - Measurement, Trends, Impacts, and Policies, 5-6 September 2014, Helsinki, Finland. 


\section{Introduction}

An effective poverty reduction policy is a relevant strategic goal for many developing economies. Scholars point out that in defining the appropriate economic policies it is essential not only to elaborate ex post poverty alleviation interventions but also to pay considerable attention to ex ante poverty prevention strategies. This understanding has led to emergence of the concept "vulnerability to poverty", which is usually defined as the probability of a household falling into poverty in the future. Application of this concept has shifted the research focus of poverty studies to trying to define the social groups that face high poverty risks as well as the determinants of such risk exposure. In the economics literature we find an overall consensus regarding the importance of assessing poverty vulnerability in order to develop an effective antipoverty protection strategy and for improvement of risk-management policies. As a result, numerous studies conceptualizing and measuring households' vulnerability to poverty (e.g., Zhang, Wan, 2009; Dutta et al., 2011; Celidoni, 2013) as well as applied research on risks of moving into poverty in different countries (e.g., Kruy et al., 2010; Angelillo, 2013; Cahyadi, Waibel, 2015) have proliferated in recent years.

We investigate vulnerability to poverty in Tajikistan during and after the global financial crisis of the late 2000's using a vulnerability measure based on a Markov transition probability matrix. ${ }^{1}$ The measure utilizes panel data and allows study of the probability of moving into poverty in the short, medium, and long-run, of particular interest in a period of great economic stress.

The objective of this paper is twofold. First, we develop and describe the application of an innovative and natural measure of poverty vulnerability based on the Markov model which identifies every household as either poor (that is, living below the poverty line) or to some degree vulnerable to poverty. This index of vulnerability is a weighted probability of a household falling into poverty over a given time horizon. This measure also allows us to look across subpopulations in identifying vulnerable subgroups. Second, we analyze how different household

\footnotetext{
${ }^{1}$ Despite numerous studies on poverty in developing countries, the attempts to analyze vulnerability to poverty in Tajikistan are very scarce with a notable exception by Jha, Dang, and Tashrifov (2010) which studies the poverty profile of the Tajik population and the risks of households' entering into poverty using a household panel data for 2004 and 2005.
} 
characteristics affect the vulnerability to poverty in Tajikistan. The emphasis is placed on the role of international migration and remittances in securing households' welfare and in reducing the risks of falling into poverty due to external economic shocks.

Tajikistan may be considered as an especially well-suited case for studying the effect of migration and remittances on the households' vulnerability to poverty because of the high incidence of international labor migration and large amount of remittances directed to the country from abroad. In 2012, Tajikistan was the world's most remittance-dependent country: the inflow of remittances amounted to US\$3.6 billion, or about $47.5 \%$ of the country's GDP (World Bank, 2015). The global financial crisis and the consequent economic recession in the main destination country of Tajikistani migrants, Russia, resulted in a sharp decline in remittances, despite considerable increase in labor migration (Danzer, Ivaschenko, 2010). With the share of yearly consumption made affordable through remittances exceeding 35\% in all welfare quintiles (Danzer et al., 2013a), we expect a shock of the size of the global financial crisis to have a large impact on Tajiki's exposure to poverty.

In our analyses, we use a three-wave panel dataset that was constructed from the 2007 and 2009 Tajikistan Living Standards Measurement Survey (TLSS) and the 2011 Tajikistan Household Panel Survey (THPS). ${ }^{2}$ These surveys contain questions on migration, education, health, labor market, housing, remittances and social assistance, subjective poverty, food security, as well as household expenditures and income. The three panel waves permit analysis of two transitions. The first is from 2007 to 2009 which coincides with the impact that the global financial crisis had on Tajikistan. The second transition from 2009 to 2011 coincides with Tajikistan's recovery from the global financial crisis. Thus, we are able to examine changes in poverty and vulnerability to poverty during a major recession and an economic expansion.

The outline of the paper is as follows: Section 0 provides a discussion on the Tajikistan's economy, poverty dynamics, and international labor migration trends as well as summarizes literature on the effect of the global financial crisis on economy and migration patterns in

\footnotetext{
${ }^{2}$ The first two waves of the survey (TLSS 2007, 2009) were administered by the World Bank and UNICEF. The third wave of the panel (THPS 2011) was designed and implemented by the Institute for the East and Southeast European Studies (IOS-Regensburg) as a follow-up of the TLSS (Danzer et al. 2013b). The same households were re-interviewed, with overlapping questions.
} 
Tajikistan. Section 0 introduces the underlying Markovian model and the vulnerability measure used in this paper and points to its advantages over other popular vulnerability measures. In section 4 we describe our data and variables while section 5 discusses our estimation strategy. In section 6 we take up the results of our analyses using the panel data from Tajikistan. Finally, in section 7 we conclude and discuss the policy relevance of our results.

\section{Poverty, migration and remittances in Tajikistan}

Tajikistan, the poorest economy of the former Soviet Union and located in Central Asia, underwent severe economic, social and political changes following the collapse of the USSR. Independence in 1991 with its rupture of economic ties was followed by civil war among rival regional clans from 1992 to 1997 and then an initially tenuous peace. By the end of the war GDP had shrunk to 35\% of its 1990 level and inflation was at 65.2\% (World Bank, 2011).

New economic policies were implemented soon after the peace accord and formation of the joint government in 1997. Over the 2001-2010 period annual real GDP grew at an 8.8\% average rate; average annual inflation was 20.7\% (World Bank, 2015). Despite these positive achievements, Tajikistan remains economically far behind other countries of the former USSR with the highest poverty rate and lowest GDP per capita. GDP per capita was US\$820 in 2010 (for comparison, in the Russian Federation - US\$10,481). Average monthly wages were US\$82.90 in 2010; about 8.5 times lower than those of the Russian Federation (Statistical Committee of CIS, 2011). In agriculture, forestry and fisheries - the traditional sectors of economy - monthly wages were US\$23.60, \$39.10 and \$41.60, respectively (Statistical Agency of Tajikistan, 2011). Together these sectors employ approximately 50\% of Tajikistan's working population.

Because of large income and wage differentials between Tajikistan and other former Soviet countries and lack of employment opportunities in the country there was significant emigration of Tajikistan's working population during the 2000's (Abdulloev et al., 2014). Labor migration from Tajikistan is characterized by several features. First, the massive emigration of the Tajik workforce has a seasonal and circular character. The median migration spell is about 7 months (Danzer et al., 2013a) and only one fifth of migrants stay abroad for over one year (Marat, 2009). Second, migrants predominantly work in low-skilled jobs in the construction 
sector, trade and services in the host country. Marat (2009) states that they occupy their own niche in the labor market and take jobs that are often not attractive to Russian citizens. Third, remittances play a crucial role: in 2011, 99\% of the returned migrants brought money home, while among those still living abroad 78\% remitted money (THPS 2011). According to the THPS 2011, most of remittances are used for consumption of food and basic necessities, house renovations and celebrations (such as weddings and other traditional ceremonies). An almost negligent percentage of remittances are used for investments into human capital or household enterprises or businesses (Danzer et al., 2013a).

In most cases migrants go to big urban centers in Russia, ${ }^{3}$ with over half of the migrants choosing Moscow as their destination. According to TLSS 2007, the majority of labor migrants are men (93.5\%), are from rural areas (76.4\% of all migrants), and have secondary education (64.36\% with no university or other post-secondary school training). The share of households having no migrant (in the respective year) decreased from 85.2\% in 2007 to $60.9 \%$ in 2011 (Danzer et al., 2013a). Over time, the socio-demographic characteristics of migrants have not changed much. From 2007 to 2011 the proportion of women among migrants slightly increased (up to 10.6\%). The average age was 31.6 years for those migrants who returned home and 28.9 years for those who were still living abroad at the time of survey in 2011. Between 2007 and 2011 more families started to send labor migrants abroad, and there is an increase in the number of labor migrants per household. There is also an increase in the proportion of households receiving remittance income and an increase in the size of the remittances.

Interestingly, the migration flow from Tajikistan did not decline in the great recession period opened by the global financial crisis in 2008-2009. Danzer and Ivaschenko (2010) find that although financial gains from migration declined in 2009 (the year of steep economic recession in Russia), migrant households sent a larger number of household members abroad. This may be interpreted as a strategy for coping with poverty and improving or at least securing a certain expenditure level. At the same time, given the importance of interpersonal networks that help new Tajik emigrants establish themselves in Russia and find jobs, thus, reducing costs and risks of migration, the further extension of migration activities seems to be a natural

\footnotetext{
${ }^{3}$ In 2007, 95.3\% of migrants chose Russia as a destination country (TLSS 2007), in 2011 over 98\% of labor migrants went to Russia for work (THPS 2011).
} 
consequence of the growing number of households with positive migration experience. Danzer and Ivaschenko (2010) find that reliance on personal contacts by Tajik emigrants leads to their clustering in major destinations (e.g., Moscow). The regional segregation of labor migrants points to a large dependency of households in Tajikistan on the economic situation in Russia.

Reacting to the crisis, Russian authorities halved the number of migrants' work permits by the end of 2008 from 4 million to 2 million (Ratha et al., 2009). This led, however, to a rise of illegal employment among migrants instead of decreasing their number. In 2008, it was estimated that around 60-65\% of labor migrants from Central Asia working in Russia had no legal status (UNDP, 2008).

Despite an economic slowdown in 2009 and 2010, Tajikistan, unlike many other postSoviet countries, experienced no severe recession. GDP growth amounted in these years to 3.8\% and 6.5\% respectively (World Bank, 2015). An internal crisis resulted in a moderate decline in industrial output in 2008-2009 (Tajikistan in Figures, 2010), while a fall in world market prices of major export commodities of Tajikistan, aluminum and cotton (IMF, 2016) caused additional tensions in the local labor market. At the end of 2008 and beginning of 2009, a large number of industrial enterprises in Tajikistan were closed, thus, stimulating unemployment growth (UNDP, 2010). There are very few and considerably divergent estimations of the real unemployment in the country ranging between 9.5 and 35\% (UNDP, 2010). It is often stated that the remarkably low figures presented by the official statistics (e.g., unemployment rate of $2.1 \%$ in 2009, according to Tajikistan in figures, 2010) do not correspond to the actual level of unemployment, because most of the unemployed do not register their status.

Different sources indicate that during the global financial crisis almost a half of the population in Tajikistan was classified as poor. According to the World Bank (2015), poverty by the headcount ratio measured at the national poverty line was $47.2 \%$ in 2009. Similarly, according to the estimation of the International Monetary Fund, based on the cost of basic demands for overall consumption, $46.7 \%$ of the population was assessed as poor by the end of 2009 (IMF, 2012). In general, a slow positive trend with respect to poverty reduction may be observed over the period between 2003 and 2009, which goes hand-in-hand with the extensive development of international labor migration practices. 


\section{Vulnerability to Poverty: A Special Form of Downward Mobility}

A straight-forward statement of what constitutes vulnerability to poverty is that it is the probability today of being in poverty in the future. Our measure contributes to ongoing research on how to capture poverty vulnerably. Recently, Celidoni and Procidano (2015) following up on Celidoni (2013) and Naudé et al. (2009) provided an excellent summary of the vulnerability issues the literature has addressed and the measures that have been developed, as well as providing an analysis of how well these indexes achieve their goals. The different measures stress alternative elements of a generalized notion of vulnerability. Dutta et. al. (2011) for example, emphasizes the importance of current standard of living. For Celidoni (2015) vulnerability instead consists of three measures of exposure to poverty: its' expected incidence, the expected poverty gap, and income volatility below the poverty line.

Vulnerability can be naturally modelled from the perspective of the dynamics of income, which is typically studied as a Markov process. Drawing on the Markov analysis, we approach vulnerability to poverty as a particular form of downward mobility. In this sense it is related to recent work of Verma, Betti and Gagliardi (2015), who discuss longitudinal aspects of poverty, "defining poverty as a matter of degree, determined by the place of the individual in the income distribution.” This theme is also touched on by Gaiha, Imai, and Kang (2011), among others. Closest to our approach is Dang and Lanjouw (2014a) and Dang, Lanjouw, Luoto and McKenzie (2014b) who suggest three groups: poor, vulnerable and secure, and suggest ways of detecting the upper and lower bounds of the vulnerable. While their measure clearly distinguishes among three different types of vulnerability, the vulnerability measure introduced in this paper is better suited for studying the poverty dynamics, vulnerability to poverty when panel data is available.

\subsection{Modelling Household Expenditure as a Markov Process}

The dynamics of poverty in Tajikistan is studied in this paper using a first order discrete state Markov chain for household expenditure. The use of Markov-chain models to study income (and expenditure) dynamics has a long history with notable contributions by Champernowne (1953) and Shorrocks (1976). The original work by Champernowne (1953) and Prais (1955) looked at income and social mobility respectively using Markov models. In the 1970's and 1980's this effort at using Markov probability matrices to measure income mobility was furthered by the 
work of Shorrocks (1976, 1978a, 1978b) and by Geweke, Marshall and Zarkin (1986a, 1986b). ${ }^{4}$ Methods similar to the ones used in this paper have been used in Gang et al. (2002, 2009), Dimova et al. (2006), and Co et al. (2009).

One of the most appealing aspects of using a Markov-chain to model household expenditure dynamics is the ability to investigate issues such as short and long-run movements into and out of poverty. The Markov assumption is a natural way of thinking about household expenditure dynamics while imposing only minimal theoretical structure. Before elaborating on how we investigate movements into and out of poverty we briefly discuss the first order discrete state Markov model. A fuller discussion of this model can be found in Geweke (2005).

Let the expenditure distribution be divided into $k$ expenditure classes. Once the expenditure classes are defined it is possible to model the dynamics of the (discrete) expenditure distribution. Let $\pi_{k t}$ be the proportion of the population households who have expenditures that fall into class $k, \mathcal{C}_{k}$, in period $t$. Another way to think of $\pi_{k t}$ is as the probability a randomly chosen household's expenditure falls in the range of expenditures that defines class $\mathcal{C}_{k}$. That is,

$$
\pi_{k t}=\operatorname{Pr}\left(h \in \mathcal{C}_{k}\right) .
$$

Let $\pi_{t}=\left(\pi_{1 t}, \ldots, \pi_{C t}\right)^{\prime}$ be the (column) vector of probabilities for each of the expenditure classes at time $t$. Therefore the variable $\pi_{t}$ defines the "state" of the world at time $t$ in terms of the (cross-sectional) expenditure distribution. The only structure that is imposed on $\pi_{t}$ is the first order Markov assumption. This assumption implies that the state of the world today is only dependent on $\pi_{t-1}$ and not on its past history beyond the most recent time period. That is,

$$
P\left(\pi_{t} \mid \pi_{t-1}, \pi_{t-2}, \ldots, \pi_{t-j}\right)=P\left(\pi_{t} \mid \pi_{t-1}\right) \quad \forall j=2,3, \ldots,
$$

\footnotetext{
${ }^{4}$ See Gang, Landon-Lane and Yun (2004) for studying a directional mobility index. Co, Landon-Lane and Yun (2006) used Markov models to test for convergence of cross-sectional distributions, which can be applied to studying changes in inequality.
} 
where $P($.$) represents the conditional (cross-sectional) probability distribution of \pi$. This firstorder Markov assumption was introduced in Champernowne (1953) and was further discussed in Shorrocks (1976).

The first order assumption is made operational by defining the Markov transition matrix $\mathbf{P}$. Define the probability of transiting from class $j$ in period $t-1$ to class $k$ in period $t$ to be $P\left(\pi_{t}=k \mid \pi_{t-1}=j\right) \equiv p_{j k}$ so that the Markov transition matrix, $\mathbf{P}$, can be defined as $\mathbf{P}=\left[p_{j k}\right]_{j=1 k=1}^{C C}=\left[p_{j k}\right]$. Then the first order discrete-state Markov chain model can be written as

$$
\pi_{t}^{\prime}=\pi_{t-1}^{\prime} \mathbf{P}
$$

Information obtained from $\mathbf{P}$ is not the only important information we can get from (3). We are also able to extract information about the dynamics of the cross-sectional distribution. Let the initial expenditure probability distribution be $\pi_{0}$. Then by (3) it follows that

$$
\pi_{1}^{\prime}=\pi_{0}^{\prime} \mathbf{P}
$$

and

$$
\pi_{2}^{\prime}=\pi_{1}^{\prime} \mathbf{P}=\pi_{0}^{\prime} \mathbf{P P}=\pi_{0}^{\prime} \mathbf{P}^{2}
$$

Thus it is simple to show that

$$
\pi_{t}^{\prime}=\pi_{0}^{\prime} \mathbf{P}^{t}
$$

The $m$-period transition probability matrix is therefore given by $\mathbf{P}^{m}$. The invariant or limiting income distribution, $\pi_{\infty}$, is any distribution that satisfies

$$
\pi_{\infty}^{\prime}=\pi_{\infty}^{\prime} \mathbf{P},
$$

and is equivalent to

$$
\pi_{\infty}^{\prime}=\lim _{t \rightarrow \infty} \pi_{0}^{\prime} \mathbf{P}^{t}
$$


The invariant distribution is unique if there is only one eigenvalue of $\mathbf{P}$ with modulus one. ${ }^{5}$ Thus we can characterize both the short-run dynamics, via the Markov transition matrix $\mathbf{P}$, and the long-run dynamics of the expenditure distribution via the limiting cross-sectional distribution $\pi_{\infty}$. Note here that $\pi_{\infty}$ is a non-linear function of $\mathbf{P}$ as it is the left eigenvector of $\mathbf{P}$ associated with the eigenvalue of $\mathbf{P}$ equal to 1 . We therefore need to estimate the parameters of the model given in (3) as well as estimate non-linear functions of those parameters.

To estimate the parameters of (3) we employ Bayesian methods. One reason we do this is so that we can obtain exact finite sample distributions for various non-linear functions of $\mathbf{P}$ that we are interested in. The functions of $\mathbf{P}$ that we are interested in include the limiting cross-sectional distribution, $\pi_{\infty}$, implied by our estimate of $\mathbf{P}$ and the measures of vulnerability developed below. While maximum likelihood estimates of $\mathbf{P}$ are easy to obtain the estimates of these nonlinear functions of $\mathbf{P}$ and more importantly the exact finite sample estimates of the standard errors of these estimates are difficult to compute. Bayesian methods, however, allow for us to easily compute the exact finite sample distributions for all non-linear functions of $\mathbf{P}$ that we are interested in.

Let $\mathbf{S}_{M T}=\left\{S_{i t}\right\}_{i=1}^{M} \quad T_{t=1}^{T}$ be the observed classes for each individual for each time period in our sample. Define the indicator variable $\delta_{i t k}$ to be 1 if individual $i$, is in category $k$, in period $t$ and 0 otherwise. That is, $\delta_{i t k}=1$ only if $s_{i t}=k$. Then the information contained in $\mathbf{S}_{M T}$ can be summarized by the following two summary statistics: $n_{0}$, the number of individuals each category initially, and $\mathbf{N}$, the data transition matrix where $n_{0 k}=\sum_{i=1}^{M} \delta_{i 0 k}$ is the number of individuals in category $k$ in the initial period and the matrix $\mathbf{N}=\left[n_{j k}\right]$ where $n_{j k}=\sum_{i=1}^{M} \sum_{t=2}^{T} \delta_{i t-1 j} \delta_{i t k}$ is the number of observed transitions from category $j$ to category $k$ across all individuals and all time periods.

\footnotetext{
${ }^{5}$ Implicitly we are assuming that the eigenvalues have been ordered from highest to lowest in terms of magnitude. As $\mathbf{P}$ is row stochastic we know that the highest eigenvalue, in terms of magnitude, is 1 . If the magnitude of the second eigenvalue is strictly less than 1 then we know that the invariant distribution is unique (Geweke, Marshall, and Zarkin, 1986b).
} 
Given these sufficient statistics, the likelihood function for this model is

$$
p\left(\mathbf{S}_{M T} \mid \pi_{0}, \mathbf{P}\right)=\prod_{j=1}^{C} \pi_{0 j}{ }^{n_{0 j}} \prod_{j=1}^{C} \prod_{k=1}^{C} p_{j k}^{n_{j k}} .
$$

This likelihood function is the product of likelihood functions for multinomial random variables and so the maximum likelihood estimators take the form

$$
\hat{p}_{j k}=\frac{n_{j k}}{\sum_{k=1}^{C} n_{j k}} .
$$

Each row of $\mathbf{P}$ is estimated independently of each other row of $\mathbf{P}$ with the maximum likelihood estimate of the transition probability of moving from class $j$ to class $k$ being the number of individuals who moved from class $j$ to class $k$ as a proportion of the number of individuals in class $j$ at the start of the period. Problems occur with this estimator when data is sparse. If the number of classes is large there is a chance that we do not observe any transitions between two classes, especially if the classes are far from each other. ${ }^{6}$

This data sparsity problem is easily handled by an appropriate choice of a prior distribution in our Bayesian analysis. We choose a conjugate prior distribution for all the unknown parameters in the model and in doing so generate a posterior distribution that can be directly sampled. As noted earlier the likelihood function takes the form of a product of independent multinomial random variables. More precisely we propose independent conjugate priors for each row of $\mathbf{P}$ and for $\pi_{0}$. Each row of $\mathbf{P}$ and $\pi_{0}$ has the same property, that is, each element is a probability and the sum of all elements is 1 . This suggests that the appropriate form of conjugate prior for $\pi_{0}$ and for each row of $\mathbf{P}$ is Dirichlet (multivariate Beta). ${ }^{7}$ A random vector, $\pi=\left(\pi_{1}, \ldots, \pi_{C}\right)$, is distributed with a Dirichlet distribution parameterized by vector $a$ if

\footnotetext{
${ }^{6}$ In our application our classes are expenditure classes and in this case it is most improbable for households to move from the lowest expenditure class to the highest expenditure class in one period. Thus we expect to see a large number of zeros in the data transition matrix $\mathbf{N}$.

${ }^{7}$ See Bernado and Smith (1994, pages 134-135) for a complete description of the Dirichlet distribution.
} 


$$
0 \leq \pi_{j} \leq 1 \text { and } \sum_{j=1}^{C} \pi_{j}=1
$$

and $\pi$ has probability density function

$$
p(\pi) \propto \pi_{1}^{a_{1}-1} \ldots \pi_{C}^{a_{C}-1}
$$

The mean for each $\pi_{j}$ is equal to $\mu_{j}=\frac{a_{j}}{\sum_{k=1}^{C} a_{k}}$, and variance for each $\pi_{j}$ is equal to $\operatorname{var}\left(\pi_{j}\right)=\frac{\mu_{j}\left(1-\mu_{j}\right)}{1+\sum_{k=1}^{C} a_{k}}$. This prior distribution is conjugate in the sense that we combined with the likelihood function the resulting posterior distribution is also a Dirichlet distribution.

In defining the prior distribution we assume independence between the prior for $\pi_{0}$ and the prior for each row of $\mathbf{P}$. Let the prior distribution for $\pi_{0}$ be parameterized by the vector $a_{0}=\left(a_{01}, \ldots, a_{0 C}\right)$ and let each row, $j$, of $\mathbf{P}$ be parameterized by the row vector $a_{j \bullet}=\left(a_{j 1}, \ldots, a_{j C}\right)$. Then the prior distribution for $\pi_{0}$ is

$$
p\left(\pi_{0}\right) \sim \operatorname{Di}\left(a_{0}\right) \propto \pi_{01}^{a_{01-1}} \ldots \pi_{0 C}^{a_{0 C}-1}
$$

and the prior distribution for the $j^{\text {th }}$ row of $\mathbf{P}$ is

$$
p\left(p_{j 1}, \ldots, p_{j C}\right) \sim \operatorname{Di}\left(a_{j \bullet}\right) \propto \pi_{j 1}^{a_{j 1}-1} \ldots \pi_{j C}^{a_{j C}-1}
$$

Putting these priors together we get the joint prior distribution for $\pi_{0}$ and $\mathbf{P}$ as

$$
p\left(\pi_{0}, \mathbf{P} \mid a_{0}, \mathbf{A}\right) \propto \prod_{j=1}^{C} \pi_{0 j}^{a_{0 j}-1} \prod_{j=1}^{C} \prod_{k=1}^{C} \pi_{j k}^{a_{j k}-1}
$$

where $\mathbf{A}=\left[a_{j k}\right]_{j=1, k=1}^{C, C}$. Combining the prior given in (10) with the likelihood given in (5) we get the posterior distribution 


$$
p\left(\pi_{0}, \mathbf{P} \mid \mathbf{S}_{M T}, a_{0}, \mathbf{A}\right) \propto \prod_{j=1}^{C} \pi_{0 j}^{a_{0 j}+n_{0 j}-1} \prod_{j=1}^{C} \prod_{k=1}^{C} \pi_{j k}^{a_{j k}+n_{j k}-1}
$$

The posterior distribution is the product of independent Dirichlet distributions parameterized by $a_{0}+n_{0}$ and $\mathbf{A}+\mathbf{N}$. Notice that any potential data sparsity problem, that is zero elements in $n_{0}$ or $\mathbf{N}$, can easily be handled through the choice of the prior. As long as the parameters $a_{0}$ and $\mathbf{N}$ do not have any zero elements then the posterior will not suffer from the data sparsity problem typically faced by the maximum likelihood estimator. Assuming a quadratic loss function the Bayes estimate for the parameters in $\pi_{0}$ and $\mathbf{P}$ are just the posterior means which are

$$
\hat{\pi}_{B, 0 j}=\frac{a_{0 j}+n_{0 j}}{\sum_{k=1}^{C}\left(a_{0 k}+n_{0 k}\right)}
$$

and

$$
\hat{p}_{B, j k}=\frac{a_{j k}+n_{j k}}{\sum_{l=1}^{C}\left(a_{j l}+n_{j l}\right)},
$$

respectively.

Note that the Bayes estimators are similar to the maximum likelihood estimators except for the contribution of the prior. However as the sample size increases (as $T \rightarrow \infty$ ), the relative contribution of the prior diminishes and in the limit the Bayes estimators converge to the maximum likelihood estimators. ${ }^{8}$ The Dirichlet prior has a notional sample interpretation which is useful for discussing the informational content of the prior relative to the sample. The prior given in (8) can be thought of as the likelihood of a notional sample with a total of $\sum_{j=1}^{C}\left(a_{0 j}-1\right)$ notional observations with $\left(a_{0 j}-1\right)$ notional observations in category $j$. Obviously this only makes sense when $a_{0 j}>1$. The smaller are the number of notional observations the lower the informational content in the prior. The ratio of the size of the notional sample from the prior to

\footnotetext{
${ }^{8}$ It should be noted here that as $\mathrm{T}$ increases the number of observed transitions increase. There is no need for the number of individuals or households to increase for this statement to be true.
} 
the size of the sample from the data is a measure of the contribution of the prior information relative to the information from the data.

The same interpretation can be given to the individual priors for each row of $\mathbf{P}$ given in (9). In this case the notional sample interpretation is that the prior is coming from a sample with $\sum_{k=1}^{C}\left(a_{j k}-1\right)$ total observations with $\left(a_{j k}-1\right)$ observed transitions from class $j$ to class $k .^{9}$ Again the smaller the number of notional observations relative to the number of observed transitions from the sample the lesser the impact of the prior on the Bayes estimates.

\subsection{Measuring Vulnerability to Poverty}

We view all households above the poverty line as vulnerable to poverty in that all of these households have a non-zero probability of falling below the poverty line in some finite period. This is in contrast to some approaches that define a cutoff (e.g. twice the poverty line) and label all households below the cutoff as vulnerable and all households above the cutoff as not vulnerable.

Because of the dynamic nature of the Markov model we are able to estimate the Markov transition matrix, $\mathbf{P}$, and hence estimate the limiting cross-sectional distribution, $\bar{\pi}$. Thus the proportion of the population that will be in poverty in the limit is $\bar{\pi}_{1}$ and the proportion of the population that would be vulnerable to poverty in the limit is $1-\bar{\pi}_{1}$. We can therefore detect if the proportions of the population in poverty or vulnerable to poverty is increasing or decreasing. This approach is in essence measuring the "stock" of households in poverty at different points in time.

Another approach to the measurement of vulnerability is to look at the "flows' into and out of poverty over time. This also can be accomplished using the Markov transition matrix, $\mathbf{P}$. The Markov transition (probability) matrix is defined to be

$$
\mathbf{P}=\left[p_{j k}\right]
$$

\footnotetext{
${ }^{9}$ It should be noted that setting $a_{j k}=1$ for all $k$ yields a uniform prior for each parameter $\pi_{j k}$ but this prior would imply zero notional observations from the prior.
} 
where $p_{j 1}$ is the probability that a household that starts in class $j$ in period $t-1$ falls into class 1 (i.e. poverty) in period. Note that the threshold of the class 1 is the poverty line in this illustration. Using the Markov transition matrix to define a measure of vulnerability which is the weighted average of the probabilities of falling into poverty in one period from a class above poverty,

$$
V^{1}(\mathbf{P})=\frac{\pi_{2 t-1} p_{21}+\ldots+\pi_{C t-1} p_{C 1}}{\pi_{2 t-1}+\ldots+\pi_{C t-1}}=\sum_{j=2}^{C} \tilde{\pi}_{j t-1} p_{j 1}
$$

where $\tilde{\pi}_{j t-1}=\frac{\pi_{j t-1}}{\sum_{k=2}^{C} \pi_{k t-1}}$ is the proportion of individuals in class $j$ out of all individuals above the poverty line in period $t-1$.

This vulnerability measure (15) is the weighted probability of moving into poverty in one period. It is the instantaneous or short run measure of vulnerability for this population. Note that the numerator of (15) is just the contribution to $\pi_{1 t}$, the proportion of the population in poverty in period $t$, from those households that were above the poverty line in period $t-1$ but fell into poverty in period $t$. This vulnerability measure is unchanged no matter how we break up the cross sectional distribution above the poverty line. If we were to define only two classes; class 1 being below the poverty line and class 2 being above the poverty line, then our measure of vulnerability to poverty, $V^{1}(\mathbf{P})$, would remain unchanged. However we might want to divide the cross-sectional distribution above the poverty line into multiple classes to better characterize the relative dynamics of the system. Still our measure of vulnerability to poverty given in (15) would remain unchanged. Therefore, the important determinant of this measure of vulnerability is the definition of the poverty line alone and not how many classes those above the poverty line are divided into.

Consider the following figure that depicts the part of the Markov transition matrix we are interested in. The probabilities that are used to construct the vulnerability index are shown in Figure 1 in bold. Our vulnerability measure just deals with this part of the transition probability 
matrix. ${ }^{10}$ There are of course many ways to aggregate the information in the first column of the transition probability matrix but the measure given in (15) is the only one that is robust to the number and definition of classes above the poverty line.

Figure 1: Measuring Vulnerability using the Markov Transition Probability Matrix

$$
\left[\begin{array}{cccc}
p_{11} & p_{12} & \ldots & p_{1 C} \\
\boldsymbol{p}_{21} & p_{22} & \ldots & p_{2 C} \\
\vdots & \vdots & \vdots & \vdots \\
\boldsymbol{p}_{C 1} & p_{C 2} & \ldots & p_{C C}
\end{array}\right]
$$

We can also introduce a measure of multi-period vulnerability. According to the Markov assumption

$$
\pi_{t+2}^{\prime}=\pi_{t}^{\prime} \mathbf{P P}=\pi_{t}^{\prime} \mathbf{P}^{2}
$$

Let

$$
\mathbf{P}^{2}=\left[p_{2, j k}\right]
$$

Then $\mathbf{P}^{2}$ is also row stochastic and $p_{2, j k}$ is the probability that a household that is in class $j$ in period $t$ moves to class $k$ in period $t+2$. Thus a two period measure of vulnerability for this example would be

$$
V^{2}(\mathbf{P})=\frac{\pi_{2 t} p_{2,21}+\ldots+\pi_{C, t} p_{2, C 1}}{\pi_{2, t}+\ldots+\pi_{C, t}}=\sum_{j=2}^{C} \tilde{\pi}_{t} p_{2, j 1}
$$

This measure is the weighted probability that a household will fall into poverty after two periods. Clearly such a measure can be defined for any period thus allowing us to measure short and long-run vulnerability.

We can thus define $m$-period measures of vulnerability. Suppose that there are $C$ classes and that these classes are ordered so that classes $\mathcal{C}_{1}, \ldots, \mathcal{C}_{p}$ are classes in which

\footnotetext{
${ }^{10}$ Note that the probability transition matrix is row stochastic - that is the rows sum to 1 -but not column stochastic. In other words the sum of the probabilities in the first column does not necessarily sum to 1 .
} 
households (or individuals) are below the poverty line and classes $\mathcal{C}_{p+1}, \ldots, \mathcal{C}_{C}$ are above the poverty line. Suppose further that the underlying Markov model has a Markov transition probability matrix equal to $\mathbf{P}$. Then the $m$-period measure of vulnerability is defined as follows;

$$
V^{m}(\mathbf{P})=\frac{\sum_{j=p+1}^{C} \pi_{j t}\left(\sum_{k=1}^{p} p_{m, j k}\right)}{\sum_{j=p+1}^{C} \pi_{j t}}=\sum_{j=p+1}^{C} \tilde{\pi}_{j} \sum_{k=1}^{p} p_{m, j k},
$$

where $p_{m, j k}$ is the $j m$-th element of $\mathbf{P}^{k}$. The $k$-period measure of vulnerability is the weighted probability that a household will fall into a class that is below the poverty line from a class above the poverty line within $m$ periods. This measure is non-negative and is only equal to 0 if all the probabilities of moving into poverty are 0 .

To summarize, vulnerability to poverty is defined as the probability today of being in poverty in the future. We contribute to ongoing research on how to capture poverty vulnerability by developing an innovative and natural measure when panel data is available. Our measure is based on the classic literature on mobility utilizing Markov process, that is, vulnerability to poverty can be measured as a special case of downward mobility. Furthermore, by introducing an m-period measure of vulnerability, we are able to look at short, medium and long-run vulnerability to poverty.

\section{Data and Variables}

As a database for the analyses conducted in this paper, we use a three-wave panel dataset that we created by merging the data from TLSS 2007, TLSS 2009 and the THPS 2011. The first two surveys were implemented to collect information on poverty and living conditions of individuals and households in Tajikistan ${ }^{11}$. Initially, 4860 households were interviewed on different topics including education, health, labor market and migration. In 2009, a random subsample of 1503 households was drawn from the sample of the TLSS 2007. The selected households were re-

\footnotetext{
${ }^{11}$ For a detailed description of the TLSS 2007 sampling procedure see the basic information document of the survey: http://microdata.worldbank.org/index.php/catalog/72/related_materials.
} 
interviewed within the TLSS 2009 study. In 2011 it was possible to re-interview 1458 households that participated in the two previous waves (Danzer et al. 2013b). Apparently, the panel attrition is very low, because only 45 households were found missing in the primary sampling units in 2011 compared to 2009. The low number of families that were not reinterviewed in 2011 points to the fact that despite high rates of labor emigration from Tajikistan these moves are characterized by temporary, seasonal visits of the destination country rather than migration of the whole migrant's family for a permanent residence. A balanced panel of 1257 households (that reported values in each year for all variables of interest) allows us analysis of two transitions, a recession transition between 2007 and 2009, and a recovery transition between 2009 and 2011.

The data on monthly household expenditures are used to determine whether a household is below or above the poverty line. Calculated from the surveys, total expenditure for a household includes total payments for good and services consumed, the market value of goods and services consumed where payment was made in kind, the market value of assets consumed, and the value of savings (or asset accumulation). Monthly expenditures are in current prices (local currency) and are reported as a total for the household. According to the World Bank (2009) on poverty in Tajikistan in 2007, the per capita poverty line, based on expenditures, was 139 Somoni. Using reported gross national expenditure indices for Tajikistan for 2009 and 2011 the poverty line for 2009 was computed to be 169 Somoni and for 2011 was computed to be 214 Somoni. ${ }^{12}$ The variable of direct interest to us is then calculated as household expenditure per household member relative to the relevant poverty line. ${ }^{13}$ This is the variable that we use in the estimation of the Markov transition matrix below. In using expenditure and not income (which is also available in the sample) we are keeping with the standard approach in the development literature based partly on theory - income is more volatile than expenditure and so the latter is a better indicator of lifetime welfare (Deaton, 1997) - and partly on the practical matter that income is more difficult to measure than expenditure (see the classic discussion on this matter in Deaton, 1997).

12 The gross national expenditure index is obtained from [last accessed 21 February 2015] http://www.indexmundi.com/facts/tajikistan/gross-national-expenditure-deflator.

${ }^{13}$ The difficulty of setting the poverty line properly is well debated in the literature (see Deaton, 1997, pp. 141-144, among others). 
Table 1 reports summary statistics and descriptions for variables of interest in our sample. The period of our sample straddles the global financial crisis and the data on income and expenditures reflect this. Monthly expenditures fall from 2007 to 2009 and then greatly increase in 2011 as the economy bounces back. Consistent with our narrative we see an increasing number of households containing migrants. We also see an increase in the proportion of households receiving remittance income and we see an increase in the size of the remittances. The rest of the variables that we look at are demographic variables that we use to characterize the household. Roughly one-third of our households live in urban areas and the average age of the head of the household is approximately 50 years old. ${ }^{14}$ An interesting feature is that the proportion of households with a female head increases from around $16 \%$ in 2007 to $24 \%$ in 2011. This is consistent with the migrant data; Tajikistan saw an increase in workers leaving for better paying jobs outside of Tajikistan. In almost all cases the person leaving was the male and often he was the head of the household. Almost $80 \%$ of the households are native Tajik with Uzbek the next highest percentage (about 20\%).

We also look at education. There are four categories: less than secondary, secondary, post-secondary (vocational) and higher education. The highest attained level is reported for each head of household and the most frequently indicated level of education is secondary education. Between $42 \%$ and $44 \%$ of the household heads in the sample have some form of post-secondary education and this proportion is fairly stable.

\footnotetext{
${ }^{14}$ The head of household was defined by the household members, approached by the interviewer. In general, the head of household was the prime for responding the questions. However, if this person was not available, the most knowledgeable person was asked to reply. Because of the strong traditional gender norms typical for Tajikistan the definition of the head of household may be biased toward older male in a family.
} 


\section{Table 1: Summary Statistics and Variable Definitions}

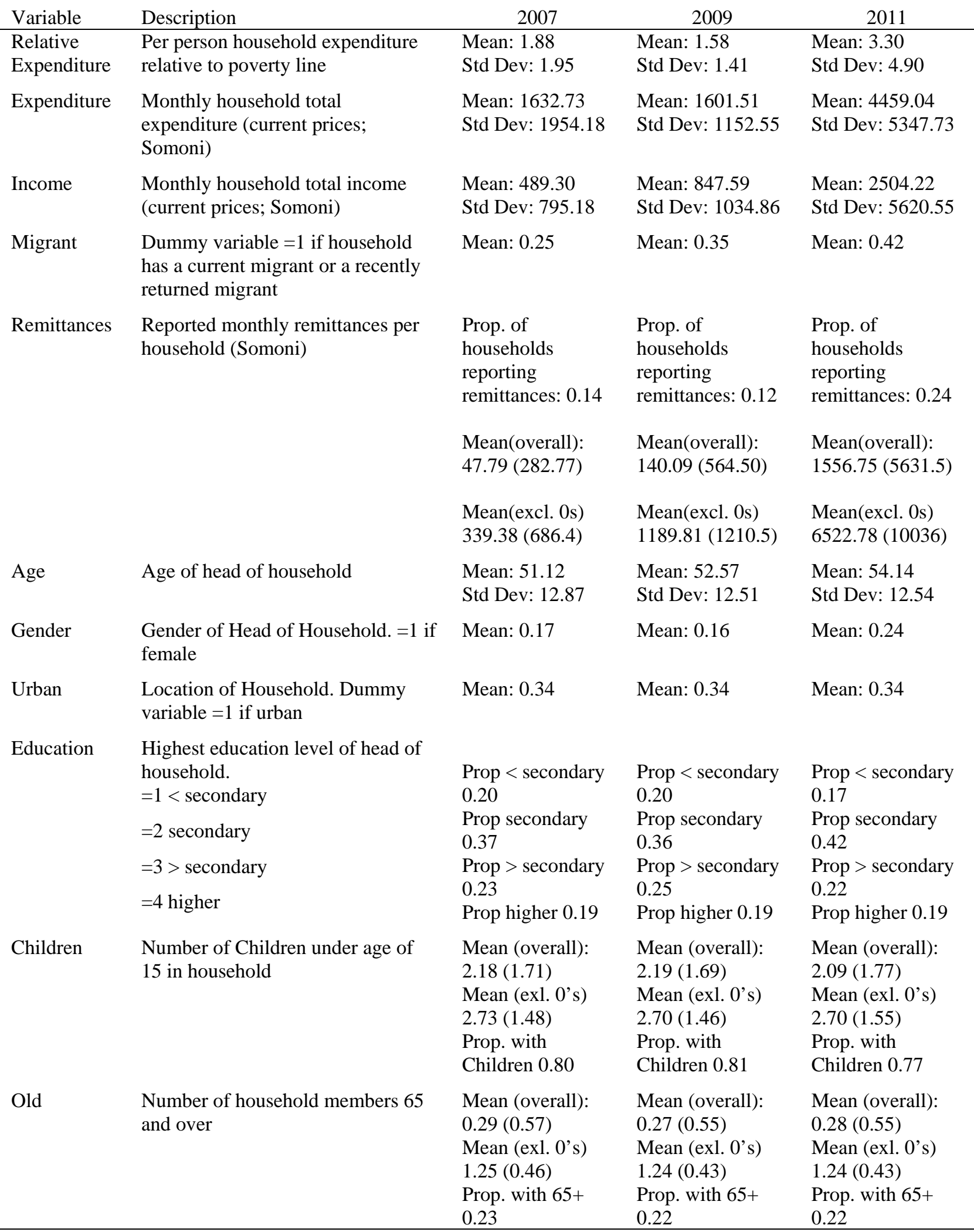

Sources: Authors' calculations using a balanced panel of households drawn from the 2007 and 2009 Tajikistan Living Standards Measurement Survey (TLSS) and the 2011 Tajikistan Household Panel Survey (THPS). 


\section{Estimating Vulnerability for Tajikistan}

We use Bayesian estimation methods to estimate the parameters of (3) as described above. ${ }^{15}$ The Markov model has two main parameters, the initial distribution $\pi_{0}$ and the Markov transition matrix $\mathbf{P}$. Before estimating the model we first need to define the expenditure classes. The definition of the expenditure classes should be done in such a way as to cover the expenditure distribution efficiently without having classes with no members. The researcher is free to define the expenditure class cutoffs above the poverty line as they see fit as the measure of vulnerability that we use is robust to the number of classes defined above the poverty line, as discussed above.

For our analysis of Tajikistan we define eleven expenditure classes covering the expenditure distribution. Since we are interested in poverty we define the first expenditure class to be those households for which per capita expenditures each month are less than the poverty line. The other expenditure classes breakup the expenditure distribution above the poverty line into judiciously fine expenditure categories. We follow a reasonably intuitive approach by defining the endpoint of each class as household expenditures per person relative to the poverty line. The exact definitions of the expenditure classes are reported in Table 2. Thus the first class includes all households who spend less than 139 Somoni per person per month. We then divide the range from the poverty line to twice the poverty line up into five classes. This range is the commonly accepted group of households that are considered to be at high risk. The rest of the distribution is divided into equally spaced classes with the highest class including every household who spend more than six times the poverty line per person in a one month period.

\footnotetext{
${ }^{15}$ For a broad overview of the estimation method see Geweke (2005, p. 229).
} 
Table 2: Expenditure Class Definitions (Relative to Poverty Line)

\begin{tabular}{ccc}
\hline Class & Lower Bound & Upper Bound \\
\hline 1 & 0 & 1 \\
2 & 1 & 1.2 \\
3 & 1.2 & 1.4 \\
4 & 1.4 & 1.6 \\
5 & 1.6 & 1.8 \\
6 & 1.8 & 2 \\
7 & 2 & 3 \\
8 & 3 & 4 \\
9 & 4 & 5 \\
10 & 5 & 6 \\
11 & 6 & 100 \\
\hline
\end{tabular}

As we are using Bayesian methods we need to define priors for the two parameters of the model, $\pi_{0}$ and $\mathbf{P}$. We use naturally conjugate Dirichlet priors for $\pi_{0}$ and for each row of $\mathbf{P}$, reporting the parameters of these priors in Table 3. The priors defined in this way have a notional sample interpretation. That is we can think of the prior probability distributions being data densities generated from a notional sample where the investigator gets to choose the sample size. In our case the prior for $\pi_{0}$ is parameterized by $a_{0}$ where $a_{0 i}-1$ can be interpreted as the number of observations in class $i$ in the notional population. Thus the smaller is the notional sample size coming via the prior the more weight is given to the information contained in the observed data that is included in the posterior density. By choosing the prior specification as given in Table 3 we are thus placing very little prior information relative to the information contained in the data on the unknown parameters of the model.

The prior for $\pi_{0}$ and the prior for each row of $\mathbf{P}$, shown in Table 3, is known as a symmetric Dirichlet distribution. The prior has the equivalent of 0.1 observations in the notional sample. That is, in the notional sample the income distribution is evenly distributed over the 
different expenditure classes. ${ }^{16}$ The prior is diffuse (but still proper) and relatively uninformative and its main use is to solve the data sparsity problem inherent in estimating first order discrete state Markov processes like this using maximum likelihood methods. Using this prior there now non-zero observations - either notional observations or actual observations - in each class and each transition. In this application the prior's main use is to solve the data sparsity issue rather than to impose any strong prior beliefs. ${ }^{17}$

\section{Table 3: Prior Parameters}

\begin{tabular}{lllllllllll}
\multicolumn{10}{c}{$a_{0}$} \\
\hline 1.1 & 1.1 & 1.1 & 1.1 & 1.1 & 1.1 & 1.1 & 1.1 & 1.1 & 1.1 & 1.1 \\
& & & & & & & & & & \\
& & & & & $A_{i}$ & & & & & \\
1.1 & 1.1 & 1.1 & 1.1 & 1.1 & 1.1 & 1.1 & 1.1 & 1.1 & 1.1 & 1.1 \\
\hline
\end{tabular}

Using these priors and the data we employ the sampling procedure suggested in Geweke (2005) to make 10,000 independent and identically distributed draws from the posterior distribution. Thus we have a set of i.i.d. draws, $\left\{\pi_{0}^{(l)}, \mathbf{P}^{(l)}\right\}_{l=1}^{L}$, from the joint posterior distribution $p\left(\pi_{0}, \mathbf{P} \mid \mathbf{S}_{M T}\right)$. We do so separately for the 2007 to 2009 transition and the 2009 and 2011 transition. We do not pool the data as it is obvious from our separate results that the transition probability matrices are quite different.

\footnotetext{
${ }^{16}$ Although equal prior weight is placed on each expenditure classification the prior is still a proper prior.

${ }^{17}$ Note that a uniform, but proper, prior over the parameters is when $a_{0}$ is set to a vector of ones and each row of $\mathbf{A}$ is also set to a vector of ones. In such a prior all combinations of values for $\pi_{0}$ and values for each row of $\mathbf{P}$ are equally likely under the prior. However for this prior the data sparsity issue is not solved. Thus our prior is close to the uniform prior whilst still addressing the data sparsity issue.
} 
Using our i.i.d. draws from the posterior distribution we can compute the posterior distribution of any well-behaved function of the underlying parameters of our model: $g\left(\pi_{0}, \mathbf{P}\right)$. For example we are interested in computing the posterior distribution of

$$
g\left(\pi_{0}, \mathbf{P}\right)=V^{m}(\mathbf{P})
$$

for $m=1,2$, and 5 . That is we compute the posterior distribution of the vulnerability to poverty over one, two, and five year time spans under the assumption that the probability transition matrix does not change.

\section{Results}

Table 4 reports vulnerability measures for Tajikistan separately for the 2007 to 2009 transition and for the 2009 to 2011 transition. ${ }^{18}$ The full results including estimates of the initial crosssectional distribution, the Markov transition probability matrix and the limiting cross-sectional distribution for each transition can be found in the Appendix. The vulnerability measures reported in Table 4 show the weighted probability of moving below the poverty line after 1 year, 2 years and 5 years respectively. For the 2007-2009 transition these probabilities are high at 31.4\%, 34.8\%, and 35.7\% respectively. Table A1 in the Appendix reports the individual probabilities of moving below the poverty line for each expenditure class. The probabilities of moving below the poverty line are all above $20 \%$ except for the highest expenditure class. This class includes all households with a per person expenditure greater than six times the poverty line. The probability of moving below the poverty line is higher for the classes closer to the poverty line but it is clear that households with expenditures greater than twice the poverty line are at risk in this transition.

\footnotetext{
${ }^{18}$ Given the significant differences between the two transitions - and the two estimated probability transition matrices - it does not make sense to pool the transitions together and report pooled estimates.
} 
Table 4: Aggregate Poverty Vulnerability, Tajikistan

(standard errors in parentheses)

\begin{tabular}{lccc}
\hline Sample & $V^{1}(\mathbf{P})$ & $V^{2}(\mathbf{P})$ & $V^{5}(\mathbf{P})$ \\
\hline $2007-09$ & One period & Two period & Five period \\
& 0.314 & 0.348 & 0.357 \\
$2009-11$ & $(0.015)$ & $(0.014)$ & $(0.015)$ \\
& 0.019 & 0.023 & 0.024 \\
& $(0.004)$ & $(0.007)$ & $(0.008)$
\end{tabular}

Sources: Authors' calculations using a balanced panel of households drawn from the 2007 and 2009 Tajikistan Living Standards Measurement Survey (TLSS) and the 2011 Tajikistan Household Panel Survey (THPS).

\begin{tabular}{ccccc}
\multicolumn{5}{c}{ Table 5: Tests for Differences in Vulnerability within Transitions } \\
Comparison & $\begin{array}{c}\text { P5\% Highest } \\
\text { Posterior Mean }\end{array}$ & $\begin{array}{c}\text { Posterior } \\
\text { Posterior Std. Dev. } \\
\text { Posterior Density } \\
\text { Region }\end{array}$ & $\begin{array}{c}\text { Probability } \\
\text { Difference }>0\end{array}$ \\
\hline $\begin{array}{c}V^{2}(\mathbf{P})-V^{1}(\mathbf{P}) \\
(2007-2009)\end{array}$ & 0.034 & 0.009 & {$[0.016,0.052]$} & 0.9997 \\
$V^{5}(\mathbf{P})-V^{1}(\mathbf{P})$ & 0.043 & 0.011 & {$[0.021,0.065]$} & 1.0000 \\
$(2007-2009)$ & & & & \\
$V^{5}(\mathbf{P})-V^{2}(\mathbf{P})$ & 0.009 & 0.003 & {$[0.003,0.015]$} & 1.0000 \\
$(2007-2009)$ & & & & \\
$V^{2}(\mathbf{P})-V^{1}(\mathbf{P})$ & 0.005 & 0.006 & {$[-0.006,0.016]$} & 0.7954 \\
$(2009-2011)$ & & & & \\
$V^{5}(\mathbf{P})-V^{1}(\mathbf{P})$ & 0.006 & 0.006 & {$[-0.005,0.019]$} & 0.8475 \\
$(2009-2011)$ & & & & \\
$V^{5}(\mathbf{P})-V^{2}(\mathbf{P})$ & 0.001 & 0.001 & {$[-0.001,0.004]$} & 0.8850 \\
$(2009-2011)$ & & &
\end{tabular}

(2009-2011)

Sources: Authors' calculations using a balanced panel of households drawn from the 2007 and 2009 Tajikistan Living Standards Measurement Survey (TLSS) and the 2011 Tajikistan Household Panel Survey (THPS).

Table 5 reports statistical tests for differences between the different period measures of vulnerability within each transition and Table 6 reports statistical tests for differences in measures in vulnerability across the two transitions.

From Table 5 we see that the two year vulnerability measure is significantly higher than the one year vulnerability measure for the 2007-2009 transition with the mean difference being 
0.034 - or 3.4 percentage points. The posterior probability that the two period vulnerability measure is greater than the one period vulnerability measure is 1 . The five-period vulnerability measure is also higher than the one-period vulnerability measure but the additional probability of falling into poverty is 0.009 - or about 1 percentage point - compared to the two year vulnerability measure. Note that the multiple period vulnerability measures are calculated under the assumption that there is no structural break in the meantime. The results reported here suggest that most of the movement into poverty occurs quickly. Another way of saying this is that the cross-sectional distribution quickly converges to its limiting distribution. One way of measuring the speed of convergence for a Markov chain is the half-life or the speed at which the chain moves half way to the limiting distribution. Shorrocks (1978b) defines the half-life of a Markov chain to be

$$
h=\frac{-\log (2)}{\log \left|\lambda_{2}\right|}
$$

where $\left|\lambda_{2}\right|$ is the magnitude of the second largest eigenvalue of $\mathbf{P} .^{19}$ The posterior mean of the magnitude of the second largest eigenvalue for the estimated probability transition matrix for the 2007-2009 transition is 0.187 so that the posterior mean value for the half-life is 0.413 . That is the chain is expected to move half way from the starting cross-sectional distribution to its limiting distribution in just under half a period. This is a very quick transition and explains why the multiple-period vulnerability measures are similar to the one-period measure.

For the first transition, from 2007 to 2009, the results are as you would expect for a country suffering from the global financial crisis. The initial expenditure distribution is clumped at the lower end of the relative expenditure distribution with 32\% of households being below the poverty line and a further 35\% of households having a per person relative expenditure above the poverty line but less than twice the poverty line (see Table A1). The first transition leads to a limiting distribution that is shifted to the left of the initial distribution. ${ }^{20}$ Figure 2 depicts the

\footnotetext{
${ }^{19}$ Recall that the largest eigenvalue of $\mathbf{P}$ is 1 as $\mathbf{P}$ is row stochastic.

${ }^{20}$ Recall that the limiting distribution is the distribution you would get after an infinite number of transitions under $\mathbf{P}$.
} 
initial and hypothetical limiting distribution with the expenditure classes between a relative expenditure of 1 and 2 aggregated together.

Table 6: Tests for Differences in Vulnerability across Transitions

\begin{tabular}{ccccc} 
Comparison & Posterior Mean & $\begin{array}{c}\text { Posterior Std. } \\
\text { Dev. }\end{array}$ & $\begin{array}{c}95 \% \text { Highest } \\
\text { Posterior Density } \\
\text { Region }\end{array}$ & $\begin{array}{c}\text { Posterior } \\
\text { Probability } \\
\text { Difference }>0\end{array}$ \\
\hline$V^{1}\left(\mathbf{P}_{0709}\right)-V^{1}\left(\mathbf{P}_{0911}\right)$ & 0.296 & 0.016 & {$[0.266,0.327]$} & 1.000 \\
$V^{2}\left(\mathbf{P}_{0709}\right)-V^{2}\left(\mathbf{P}_{0911}\right)$ & 0.325 & 0.016 & {$[0.294,0.357]$} & 1.000 \\
$V^{5}\left(\mathbf{P}_{0709}\right)-V^{5}\left(\mathbf{P}_{0911}\right)$ & 0.333 & 0.017 & {$[0.300,0.366]$} & 1.000
\end{tabular}

Sources: Authors' calculations using a balanced panel of households drawn from the 2007 and 2009 Tajikistan Living Standards Measurement Survey (TLSS) and the 2011 Tajikistan Household Panel Survey (THPS).

Figure 2: Cross-Sectional Relative Expenditure Distributions for 2007-2009 Transition

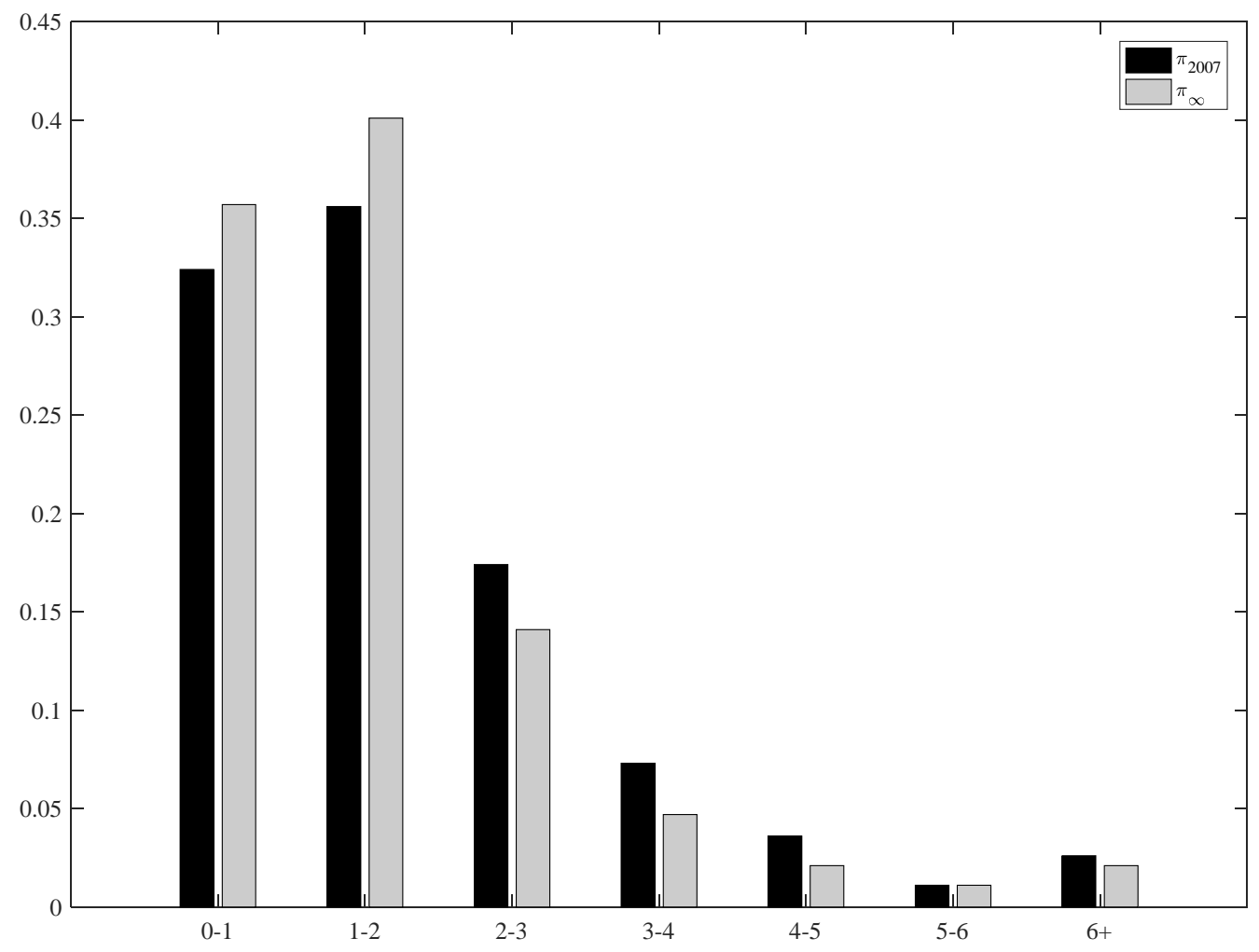


Figure 3: Cross-Sectional Relative Expenditure Distributions for 2009-2011

\section{Transition}

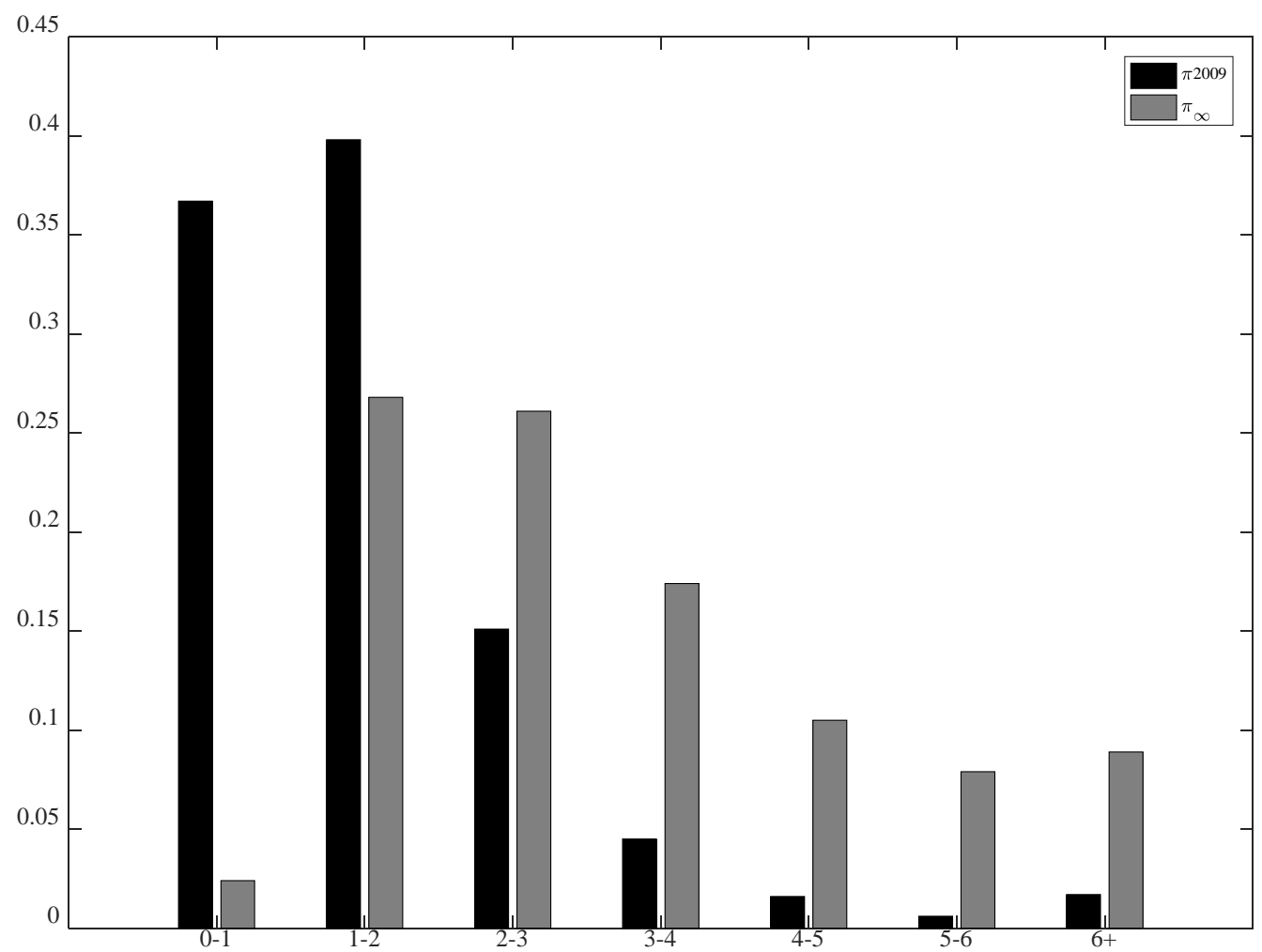

The next transition is from 2009-2011 and this was a transition where Tajikistan was recovering from the effects of the global economic crisis. This is evident in the results. The initial distribution for 2009 is similar to what we saw in 2007 with the largest proportions of households in the lowest few expenditure classes. The estimates for the initial distribution in 2009 are reported in Table A2 (in the Appendix) and Figure 3. This recovery transition yields a vastly different limiting distribution as we see in Figure 3. The recovery period from 2009-2011 is clearly a period of rising incomes and expenditures. These are relatively good times for Tajikistan and this is evident in the vulnerability measures as well. The vulnerability measures for a one year transition, two years and five years are 0.019, 0.023 and 0.024 respectively. The individual probabilities in Table A2 also show that there is no expenditure class with a probability of moving below the poverty line above 5\%. Therefore in this transition very few households are at risk or vulnerable and certainly households whose initial expenditures are less 
than twice the poverty line could not be considered especially vulnerable in this transition. In the second transition (2009-2011) there are no statistical differences between the one-period and multiple-period vulnerability measures. They are all very close to 0 . The magnitude of the second eigenvalue for this transition is 0.176 , which again leads to a very fast convergence to the limiting distribution.

Table 7 reports the vulnerability measures for both transitions for different subgroups of the population. Since the 2007-2009 transition is a transition where there is significant vulnerability we will discuss that transition in more detail. In the 2009-2011 transition all subgroups have similar low vulnerabilities and for brevity are not discussed here. We first look at urban households. About a third of the population lives in urban areas and urban households are significantly less vulnerable than rural households. The vulnerability measures for urban households are approximately equal to 0.2 whilst the vulnerability measures for rural households are between 0.35 and 0.40 . Rural households have about 17 percentage points higher probability of falling into poverty and this is significant at the $5 \%$ level as the $95 \%$ highest posterior density region (HPD) does not include 0 . This is clear evidence that rural households are more vulnerable to poverty compared to urban households in Tajikistan.

Next we look at education. When we divide the population up by education we also get expected results. Assigning households with their highest educational attainment being greater than secondary school we see these households with vulnerability measures approximately equal to 0.25 . That is, the probability of households with high educational attainment currently above the poverty line falling below the poverty line is 0.245 . For households with low educational attainment the vulnerability measures range from 0.34 to 0.39 . This is approximately 0.1 higher than for more educated households and the 95\% HPD for each measure of vulnerability does not include 0 . 
Table 7: Measures of Vulnerability to Poverty, Tajikistan: By Subgroup (standard errors in parentheses, 95\% Highest posterior density regions in square brackets)

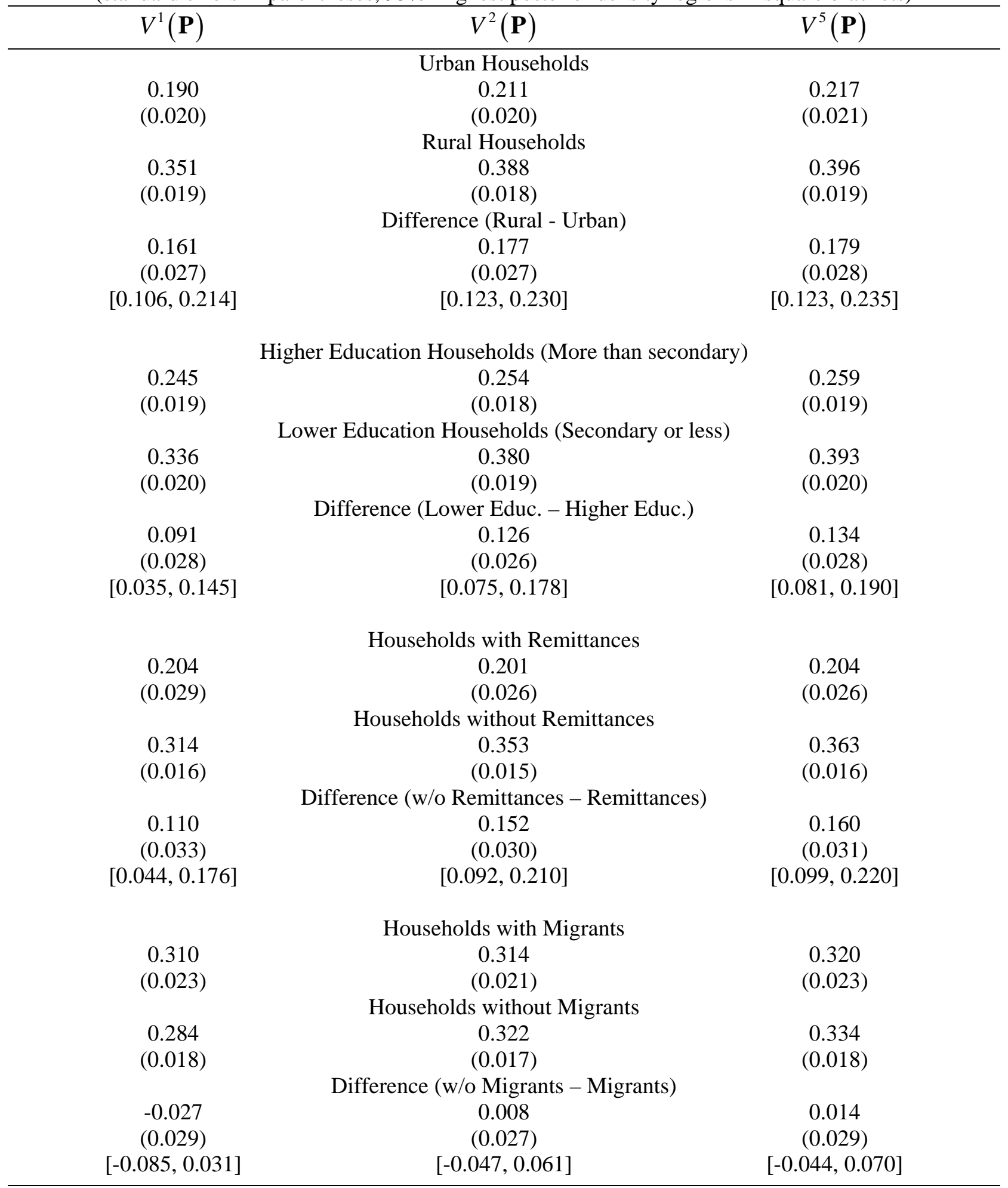

Sources: Authors' calculations using a balanced panel of households drawn from the 2007 and 2009 Tajikistan Living Standards Measurement Survey (TLSS) and the 2011 Tajikistan Household Panel Survey (THPS) 
The last sub-groups we looked at were related to international migration. We divided households up in two ways. First, we divided households up into those with current or past migrants versus those without any migrants. Second, we divided households up into those that received remittances and those that did not. The results suggest that households that had migrants had vulnerability measures ranging from 0.31 to 0.32 , while households without migrants had vulnerability measures ranging from 0.28 to 0.33 . The difference in vulnerability to poverty between households with a migrant and those without a migrant is not significant. On the other hand, the results show that households that receive remittances are less vulnerable than those that did not receive remittances. Households that did receive remittances had vulnerability measures of approximately 0.20 whilst the households that did not receive remittances had vulnerability measures ranging from 0.31 to 0.36 . The difference in vulnerability ranges from eleven to sixteen percentage points and is significant at the 5\% level given that all 95\% HPD regions do not include 0. It may mean that having a migrant is therefore not enough to protect a household from poverty; the migrant needs to be sending back remittances in order for there to be a noticeable decrease in a household's vulnerability.

\section{Discussion and Conclusion}

Vulnerability is the situation where a household is above the poverty line but there is concern that it may fall into poverty. Vulnerability has to do with a household's susceptibility to poverty - to what extent households are "at risk" of moving into poverty. This paper examines vulnerability to poverty in Tajikistan during the global financial crisis while devising an innovative and natural vulnerability measure as a special form of downward mobility relying on classic studies of mobility. This vulnerability measure is based on the notion that all households are potentially vulnerable to poverty, even wealthy households, but to different extents.

We use a first order discrete state Markov model to model expenditure and poverty dynamics. The appeal of the Markov assumption is that it imposes very little in terms of structure on the model. This allows us to measure expenditure and poverty dynamics as functions of the underlying parameters of the Markov model. In particular, we are able to investigate movements up and down the income distribution. By discretizing the expenditure distribution appropriately and by appropriately we mean in context to defined poverty lines - we are able to measure 
movements into and out of poverty. Using a measure of vulnerability to poverty as the weighted probability of a household falling into poverty over a given horizon enables us to look at short, medium and long-run vulnerability to poverty in a way that allows formal statistical testing.

We use a household panel from Tajikistan that covers the years starting in 2007 and ending in 2011 which enables us to look at vulnerability in two distinct types of economic climates. The first transition from 2007 to 2009 was a period of recession in Russia, the major destination country of Tajik migrants, while the second period from 2009 to 2011 coincided with a brisk recovery from recession.

During the recession transition almost all households were vulnerable to poverty while during the recovery period few households were vulnerable to poverty. Looking at the first transition in more detail we find separately lower vulnerability to poverty among urban and more educated households, and households receiving remittances from overseas. Interestingly, households with a current or very recently returned migrant did not have a significantly lower measured vulnerability to poverty; only those households receiving remittances from migrants had a lower vulnerability to poverty.

Over time, international labor migration became a widespread livelihood strategy in Tajikistan. Household reliance on remittances made Tajikistan sensitive and vulnerable to global economic shocks, where economic returns from migration drop as soon as a crisis hits the destination country. In the current situation this means that the welfare of many households in Tajikistan is largely dependent on the economic situation in Russia. As a result, Tajik households need to be prepared for declining remittances following economic recession and in times of economic crises. Households that receive remittances from labor migration appear to be vulnerable to poverty in the period of economic recession in Russia. This means that remittances may not be considered as a reliable and forward-looking strategy of poverty prevention and reduction, because receipt of earnings from labor migration may reduce vulnerability of households to poverty only in times of favorable economic situation in the destination country. Various external economic shocks and internal political decisions in Russia may negatively affect Russian economy and lead to a reduction of remittances flow to Tajikistan, making remittance-dependent households highly vulnerable to poverty. 


\section{References}

Abdulloev, I., Gang, I. N., \& Yun, M. S. (2014). Migration, education and the gender gap in labour force participation. European Journal of Development Research, 26(4), 509-526.

Angelillo, N. (2014). Vulnerability to poverty in China: a subjective poverty line approach. Journal of Chinese Economic and Business Studies, 12(4), 315-331.

Cahyadi, E.R., \& Waibel, H. (2015). Contract Farming and Vulnerability to Poverty among Oil Palm Smallholders in Indonesia. The Journal of Development Studies, DOI: 10.1080/00220388.2015.1098627

Celidoni, M. (2013). Vulnerability to poverty: An empirical comparison of alternative measures. Applied Economics, 45(12), 1493-1506.

Celidoni, M. (2015). Decomposing vulnerability to poverty. Review of Income and Wealth, 61(1), 59-74.

Celidoni, M., \& Procidano, I. (2015). Identification Precision of Vulnerability to Poverty Indexes: Does Information Quantity Matter?. Social Indicators Research, 121(1), 93-113.

Champernowne, D. G. (1953). A model of income distribution. Economic Journal, 63(250), 318351.

Co, C. Y., Landon-Lane, J. S., \& Yun, M.-S. (2006). Inter-state dynamics of invention activities, 1930-2000. Journal of Applied Econometrics, 21(8), 1111-1134.

Dang, H. A., \& Lanjouw, P. (2014a). Welfare dynamics measurement: two definitions of a vulnerability line and their empirical application. World Bank Policy Research Working Paper, (6944). http://dx.doi.org/10.1596/1813-9450-6944 [Accessed: 13 December 2015].

Dang, H. A., Lanjouw, P., Luoto, J., \& McKenzie, D. (2014b). Using repeated cross-sections to explore movements into and out of poverty. Journal of Development Economics, 107(March), 112-128.

Danzer, A. M., Dietz, B., \& Gatskova, K. (2013a). Tajikistan household panel survey: migration, remittances and the labor market: Survey report. IOS-Regensburg. http://www.iosregensburg.de/fileadmin/doc/VW_Project/Booklet-TJ-web.pdf [Accessed: 05 December 2014].

Danzer, A. M., Dietz, B., \& Gatskova, K. (2013b). Migration and remittances in Tajikistan: survey technical report. http://ideas.repec.org/p/ost/wpaper/327.html [Accessed: 05 December 2014].

Danzer, A. M., Ivaschenko, O. (2010). Migration patterns in a remittances dependent economy: Evidence from Tajikistan during the global financial crisis. Migration Letters 7(2), 190-202.

Deaton, A. (1997). The analysis of household surveys: A microeconometric approach to development policy. Washington, D.C.: The World Bank. http://go.worldbank.org/UWQRT802H0 [Accessed: 13 December 2015].

Devroye, L. (2006). Non-Uniform Random Variate Generation. Springer-Verlag, New York.

Dimova, R., Gang, I. N., \& Landon-Lane, J.S. (2006). The informal sector during crisis and transition in Guha-Khasnobis, B. and Kanbur, B. (eds) Informal Labour Markets and Development, 88-108, Palgrave-McMillan Press, New York. 
Dutta, I., Foster, J., \& Mishra, A. (2011). On measuring vulnerability to poverty. Social Choice and Welfare 37(4), 743-761.

Gaiha, R., Imai, K. S., \& Kang, W. (2011). Vulnerability and poverty dynamics in Vietnam. Applied Economics, 43(25), 3603-3618.

Gang, I. N., Landon-Lane, J. S., \& Yun, M.-S. (2002). Gender differences in German upward income mobility. Schmollers Jahrbuch: Journal of Applied Social Science Studies/Zeitschrift für Wirtschafts-und Sozialwissenschaften, 123(1), p3-14.

Gang, I. N., Landon-Lane, J. S., \& Yun, M.-S. (2004). Good and bad mobility: A note on directional mobility Measures. Mimeo, Department of Economics, Rutgers University.

Gang, I. N., Landon-Lane, J., \& Yun, M.-S. (2009). Measuring income assimilation of migrants to Germany. Schmollers Jahrbuch: Journal of Applied Social Science Studies/Zeitschrift für Wirtschafts-und Sozialwissenschaften, 129(2), 333-342.

Geweke, J. (2005). Contemporary Bayesian Econometrics and Statistics. John Wiley \& Sons, New York.

Geweke, J., Marshall, R. C., \& Zarkin, G. A. (1986a). Mobility Indices in Continuous Time Markov Chains. Econometrica, 54(6), 1407-1423.

Geweke, J., Marshall, R. C., \& Zarkin, G. A. (1986b). Exact inference for continuous time Markov chain models. Review of Economic Studies, 53(4), 653-669.

IMF (2012). International Monetary Fund. Republic of Tajikistan: Poverty Reduction Strategy Paper. IMF Country Report No. 12/33. Available at: https://www.imf.org/external/pubs/ft/scr/2012/cr1233.pdf [Accessed 2 February 2016].

IMF (2016). International Monetary Fund. Primary Commodity Prices. Monthly data. Available at: http://www.imf.org/external/np/res/commod/index.aspx [Accessed 2 February 2016].

Jha, R., T. Dang, Y. Tashrifov (2010). Economic vulnerability and poverty in Tajikistan. Economic Change and Restructuring. Vol. 43(2), 95-112.

Kruy, N., Kim, D., Kakinaka, M. (2010). Poverty and Vulnerability: An Examination of Chronic and Transient Poverty in Cambodia. International Area Review, 13(4), 3-23.

Marat, E. (2009). Labor migration in Central Asia: Implications of the global economic crisis. Central Asia-Caucasus Institute. Silk Road Paper, May 2009. http://www.isdp.eu/images/stories/isdp-main-pdf/2009_marat_labor-migration-in-centralasia.pdf [Accessed 13 December 2015].

Naudé, W., Santos-Paulino, A. U., McGillivray, M. (2009). Measuring Vulnerability: An Overview and Introduction. Oxford Development Studies, 37(3), 183-191.

Prais, S. (1955). Measuring social mobility. Journal of the Royal Statistical Society. Series A (General), 118(1), 56-66.

Ratha, D., Mohapatra, S., Silwal, A. (2009). Outlook for Remittance Flows 2009-2011: Remittances Expected to Fall by 7-10 Percent in 2009. Migration and Development Brief 10. World Bank, Washington, DC.

Shorrocks, A. F. (1976). Income mobility and the markov assumption. Economic Journal, 86(343), 566-578. 
Shorrocks, A. (1978a). Income inequality and income mobility. Journal of Economic Theory, 19(2), 376-393.

Shorrocks, A. F. (1978b). The measurement of mobility. Econometrica, 46(5), 1013-1024.

Statistical Agency of Tajikistan (2011). Database. http://stat.tj/ru/database/real-sector/ [Accessed 22 February 2015].

Statistical Committee of CIS (2011) Average monthly nominal wage in the CIS countries, in national currency. http://www.cisstat.com/rus/macro/1-zp_val.pdf [Accessed 22 February 2015].

Tajikistan in Figures (2010). Agency of Statistics under President of the Republic of Tajikistan. Available at: http://www.stat.tj/ru/img/9f5268b192177e16d1066c1e16aea04a_1287832044.pdf [Accessed 2 February 2016].

UNDP (2008). United Nations Development Programme. National Human Development Report:

Russian Federation. Russia Facing Demographic Challenges. Available at: http://hdr.undp.org/sites/default/files/nhdr_russia_2008_eng.pdf [Accessed 2 February 2016].

UNDP (2010). United Nations Development Programme. National Human Development Report 2008-2009. Tajikistan. Employment in the context of human development. Available at: http://hdr.undp.org/sites/default/files/tajikistan2009_eng.pdf [Accessed 2 February 2016].

Verma, V., Betti, G., \& Gagliardi, F. Fuzzy Measures of Longitudinal Poverty in a Comparative Perspective. Social Indicators Research, 1-20.

World Bank (2009). Republic of Tajikistan poverty assessment: Report no. 51341-TJ. https://openknowledge.worldbank.org/handle/10986/3159 [Accessed 20 December 2015].

World Bank (2011). Migration and remittances. Factbook 2011. Second edition. http://siteresources.worldbank.org/INTLAC/Resources/Factbook2011-Ebook.pdf [Accessed 20 February 2015].

World Bank (2015). World development indicators database. http://databank.worldbank.org/data/views/variableselection/selectvariables.aspx?source=worlddevelopment-indicators [Accessed 20 February 2015].

Zhang, Y., Wan, G. (2009). How Precisely Can We Estimate Vulnerability to Poverty? Oxford Development Studies, 37(3), 277-287. 


\section{Appendix}

Table A1: Estimation Results for 2007-2009 Transition

Initial Distribution: $\pi_{2007}$

\begin{tabular}{|c|c|c|c|c|c|c|c|c|c|c|}
\hline $\begin{array}{c}0.324 \\
(0.013)\end{array}$ & $\begin{array}{c}0.077 \\
(0.008)\end{array}$ & $\begin{array}{c}0.077 \\
(0.007)\end{array}$ & $\begin{array}{c}0.076 \\
(0.007)\end{array}$ & $\begin{array}{c}0.076 \\
(0.007)\end{array}$ & $\begin{array}{c}0.05 \\
(0.006)\end{array}$ & $\begin{array}{c}0.174 \\
(0.011)\end{array}$ & $\begin{array}{c}0.073 \\
(0.007)\end{array}$ & $\begin{array}{c}0.036 \\
(0.005)\end{array}$ & $\begin{array}{c}0.011 \\
(0.003)\end{array}$ & $\begin{array}{c}0.026 \\
(0.004)\end{array}$ \\
\hline \multicolumn{11}{|c|}{ Markov Transition Matrix: $\mathbf{P}$} \\
\hline 0.418 & 0.133 & 0.086 & 0.088 & 0.057 & 0.036 & 0.135 & 0.029 & 0.007 & 0.007 & 0.005 \\
\hline$(0.024)$ & $(0.017)$ & $(0.014)$ & $(0.014)$ & $(0.011)$ & $(0.009)$ & $(0.017)$ & $(0.008)$ & $(0.004)$ & $(0.004)$ & $(0.003)$ \\
\hline 0.368 & 0.083 & 0.102 & 0.056 & 0.056 & 0.074 & 0.157 & 0.038 & 0.029 & 0.01 & 0.028 \\
\hline$(0.047)$ & $(0.026)$ & $(0.029)$ & $(0.022)$ & $(0.022)$ & $(0.025)$ & $(0.035)$ & $(0.018)$ & $(0.016)$ & $(0.010)$ & $(0.016)$ \\
\hline 0.380 & 0.168 & 0.149 & 0.047 & 0.065 & 0.029 & 0.047 & 0.075 & 0.019 & 0.01 & 0.01 \\
\hline$(0.047)$ & $(0.036)$ & $(0.034)$ & $(0.020)$ & $(0.024)$ & $(0.016)$ & $(0.020)$ & $(0.025)$ & $(0.013)$ & $(0.010)$ & $(0.010)$ \\
\hline 0.308 & 0.114 & 0.066 & 0.085 & 0.085 & 0.067 & 0.132 & 0.066 & 0.029 & 0.01 & 0.038 \\
\hline$(0.044)$ & $(0.031)$ & $(0.024)$ & $(0.027)$ & $(0.027)$ & $(0.024)$ & $(0.033)$ & $(0.024)$ & $(0.016)$ & $(0.010)$ & $(0.018)$ \\
\hline 0.352 & 0.066 & 0.047 & 0.085 & 0.102 & 0.038 & 0.195 & 0.047 & 0.019 & 0.019 & 0.029 \\
\hline$(0.046)$ & $(0.024)$ & $(0.020)$ & $(0.027)$ & (0.029) & $(0.018)$ & $(0.038)$ & $(0.020)$ & $(0.013)$ & $(0.013)$ & $(0.016)$ \\
\hline 0.258 & 0.109 & 0.136 & 0.069 & 0.056 & 0.109 & 0.123 & 0.042 & 0.056 & 0.015 & 0.028 \\
\hline$(0.051)$ & $(0.036)$ & $(0.039)$ & $(0.029)$ & $(0.027)$ & $(0.036)$ & $(0.038)$ & $(0.023)$ & $(0.027)$ & $(0.014)$ & $(0.019)$ \\
\hline 0.358 & 0.082 & 0.091 & 0.096 & 0.052 & 0.048 & 0.177 & 0.057 & 0.022 & 0.005 & 0.013 \\
\hline$(0.032)$ & $(0.018)$ & $(0.019)$ & $(0.019)$ & $(0.015)$ & $(0.014)$ & $(0.025)$ & $(0.015)$ & $(0.010)$ & $(0.005)$ & $(0.008)$ \\
\hline 0.204 & 0.079 & 0.069 & 0.088 & 0.088 & 0.069 & 0.176 & 0.108 & 0.02 & 0.03 & 0.069 \\
\hline (0.039) & $(0.026)$ & $(0.025)$ & $(0.028)$ & $(0.028)$ & $(0.025)$ & $(0.037)$ & $(0.030)$ & $(0.014)$ & $(0.017)$ & $(0.025)$ \\
\hline 0.212 & 0.089 & 0.107 & 0.16 & 0.089 & 0.072 & 0.159 & 0.019 & 0.019 & 0.037 & 0.037 \\
\hline$(0.053)$ & $(0.037)$ & $(0.040)$ & $(0.048)$ & $(0.038)$ & $(0.034)$ & $(0.047)$ & $(0.018)$ & $(0.018)$ & $(0.024)$ & $(0.025)$ \\
\hline 0.204 & 0.084 & 0.123 & 0.083 & 0.044 & 0.084 & 0.084 & 0.044 & 0.084 & 0.044 & 0.123 \\
\hline$(0.079)$ & $(0.055)$ & $(0.063)$ & $(0.054)$ & $(0.040)$ & $(0.054)$ & $(0.054)$ & $(0.040)$ & $(0.055)$ & $(0.040)$ & $(0.064)$ \\
\hline 0.184 & 0.07 & 0.138 & 0.07 & 0.07 & 0.071 & 0.206 & 0.048 & 0.07 & 0.025 & 0.048 \\
\hline$(0.058)$ & $(0.038)$ & $(0.052)$ & $(0.038)$ & $(0.038)$ & $(0.039)$ & $(0.060)$ & $(0.031)$ & $(0.038)$ & $(0.024)$ & $(0.032)$ \\
\hline \multicolumn{11}{|c|}{ Limiting Distribution: $\pi_{\infty}$} \\
\hline 0.357 & 0.111 & 0.094 & 0.081 & 0.064 & 0.051 & 0.141 & 0.047 & 0.021 & 0.011 & 0.021 \\
\hline$(0.015)$ & $(0.009)$ & (0.009) & $(0.007)$ & $(0.007)$ & $(0.006)$ & $(0.010)$ & $(0.006)$ & $(0.004)$ & $(0.003)$ & $(0.004)$ \\
\hline Sources: & uthors' & ( & (1) & (2) & 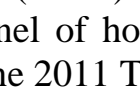 & . & 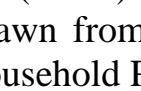 & 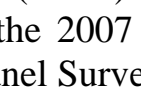 & 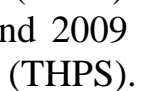 & 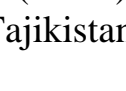 \\
\hline
\end{tabular}


Table A2: Estimation Results for 2009-2011 Transition Initial Distribution: $\pi_{2009}$

\begin{tabular}{|c|c|c|c|c|c|c|c|c|c|c|}
\hline $\begin{array}{c}0.367 \\
(0.014)\end{array}$ & $\begin{array}{c}0.108 \\
(0.009)\end{array}$ & $\begin{array}{c}0.093 \\
(0.008)\end{array}$ & $\begin{array}{c}0.084 \\
(0.008)\end{array}$ & $\begin{array}{c}0.064 \\
(0.007)\end{array}$ & $\begin{array}{c}0.049 \\
(0.006)\end{array}$ & $\begin{array}{c}0.151 \\
(0.010)\end{array}$ & $\begin{array}{c}0.045 \\
(0.006)\end{array}$ & $\begin{array}{c}0.016 \\
(0.004)\end{array}$ & $\begin{array}{c}0.006 \\
(0.002)\end{array}$ & $\begin{array}{c}0.017 \\
(0.004)\end{array}$ \\
\hline \multicolumn{11}{|c|}{ Markov Transition Matrix: P } \\
\hline 0.034 & 0.038 & 0.036 & 0.059 & 0.072 & 0.074 & 0.332 & 0.187 & 0.086 & 0.025 & 0.057 \\
\hline$(0.008)$ & $(0.009)$ & $(0.009)$ & $(0.011)$ & $(0.012)$ & $(0.012)$ & $(0.021)$ & $(0.018)$ & $(0.013)$ & $(0.007)$ & $(0.011)$ \\
\hline 0.014 & 0.041 & 0.034 & 0.069 & 0.014 & 0.081 & 0.338 & 0.216 & 0.089 & 0.055 & 0.048 \\
\hline$(0.010)$ & $(0.016)$ & $(0.015)$ & $(0.021)$ & $(0.010)$ & $(0.022)$ & $(0.039)$ & $(0.034)$ & $(0.023)$ & $(0.019)$ & $(0.017)$ \\
\hline 0.024 & 0.016 & 0.016 & 0.055 & 0.055 & 0.093 & 0.342 & 0.117 & 0.141 & 0.086 & 0.055 \\
\hline$(0.013)$ & $(0.011)$ & $(0.011)$ & $(0.020)$ & $(0.020)$ & $(0.025)$ & $(0.042)$ & $(0.028)$ & $(0.030)$ & $(0.024)$ & $(0.020)$ \\
\hline 0.027 & 0.035 & 0.035 & 0.035 & 0.086 & 0.044 & 0.342 & 0.266 & 0.069 & 0.035 & 0.027 \\
\hline$(0.015)$ & $(0.017)$ & $(0.017)$ & $(0.017)$ & $(0.026)$ & $(0.019)$ & $(0.043)$ & $(0.040)$ & $(0.023)$ & $(0.017)$ & (0.015) \\
\hline 0.023 & 0.023 & 0.045 & 0.055 & 0.077 & 0.077 & 0.295 & 0.197 & 0.088 & 0.044 & 0.077 \\
\hline$(0.015)$ & $(0.016)$ & $(0.021)$ & $(0.024)$ & $(0.028)$ & $(0.028)$ & $(0.047)$ & $(0.042)$ & $(0.030)$ & $(0.021)$ & (0.028) \\
\hline 0.015 & 0.015 & 0.029 & 0.029 & 0.097 & 0.07 & 0.315 & 0.125 & 0.083 & 0.124 & 0.097 \\
\hline$(0.014)$ & $(0.014)$ & $(0.020)$ & $(0.020)$ & $(0.035)$ & $(0.030)$ & $(0.054)$ & $(0.038)$ & $(0.032)$ & (0.039) & (0.034) \\
\hline 0.005 & 0.025 & 0.044 & 0.055 & 0.055 & 0.114 & 0.267 & 0.232 & 0.079 & 0.04 & 0.084 \\
\hline$(0.005)$ & $(0.011)$ & $(0.014)$ & $(0.016)$ & $(0.016)$ & $(0.022)$ & $(0.031)$ & $(0.029)$ & $(0.019)$ & $(0.014)$ & (0.019) \\
\hline 0.031 & 0.031 & 0.045 & 0.104 & 0.046 & 0.031 & 0.207 & 0.119 & 0.149 & 0.134 & 0.104 \\
\hline$(0.021)$ & $(0.021)$ & $(0.025)$ & $(0.037)$ & $(0.025)$ & $(0.021)$ & $(0.049)$ & (0.039) & $(0.043)$ & $(0.041)$ & (0.037) \\
\hline 0.035 & 0.035 & 0.036 & 0.068 & 0.068 & 0.035 & 0.163 & 0.165 & 0.163 & 0.067 & 0.165 \\
\hline$(0.032)$ & $(0.032)$ & $(0.033)$ & $(0.044)$ & $(0.044)$ & $(0.033)$ & $(0.065)$ & $(0.066)$ & $(0.066)$ & $(0.044)$ & (0.065) \\
\hline 0.061 & 0.06 & 0.062 & 0.116 & 0.06 & 0.061 & 0.282 & 0.061 & 0.116 & 0.06 & 0.061 \\
\hline$(0.054)$ & $(0.054)$ & $(0.055)$ & $(0.074)$ & $(0.055)$ & $(0.055)$ & (0.103) & $(0.055)$ & $(0.074)$ & $(0.055)$ & (0.055) \\
\hline 0.033 & 0.033 & 0.034 & 0.033 & 0.033 & 0.094 & 0.244 & 0.184 & 0.064 & 0.154 & 0.094 \\
\hline$(0.031)$ & $(0.031)$ & $(0.031)$ & $(0.031)$ & $(0.030)$ & $(0.050)$ & $(0.073)$ & $(0.067)$ & $(0.042)$ & $(0.062)$ & $(0.050)$ \\
\hline \multicolumn{11}{|c|}{ Limiting Distribution: $\pi_{\infty}$} \\
\hline 0.024 & 0.031 & 0.041 & 0.065 & 0.059 & 0.072 & 0.261 & 0.174 & 0.105 & 0.079 & 0.089 \\
\hline$(0.008)$ & $(0.008)$ & (0.009) & $(0.011)$ & $(0.010)$ & $(0.010)$ & $(0.018)$ & $(0.015)$ & $(0.015)$ & $(0.012)$ & (0.013) \\
\hline
\end{tabular}

